\title{
In-situ TEM cooling/heating experiments on deformed NiTi shape memory single crystals
}

\author{
T. Simon ${ }^{\text {a1 }}$, A. Kröger ${ }^{1}$, Ch. Somsen ${ }^{1}$, A. Dlouhy ${ }^{2}$ and G. Eggeler ${ }^{1}$ \\ ${ }^{1 \cdot}$ Ruhr-University Bochum, Institute for Materials, 44780 Bochum, Germany \\ ${ }^{2}$ Institue of Physics of Materials, ASCR, Ziskova 22, 61662 Brno, Czech Republic
}

\begin{abstract}
In the present study we report about the influence of dislocations on martensitic transformations in NiTi single crystals. Microstructural investigations are performed on $\mathrm{Ni}_{50.4} \mathrm{Ti}_{49.6}$ (at.\%) single crystals using in-situ cooling and heating transmission electron microscopy (TEM). Solution heat-treated $\mathrm{Ni}_{50.4} \mathrm{Ti}_{49.6}$ single crystals were oriented by electron backscatter diffraction (EBSD) and compressed in $[111]_{\mathrm{B} 2}$-direction to different strain levels. DSC measurements on undeformed and deformed material states reveal a two step transformation from B2 to R-phase and then from R-phase to B19' confirmed by TEM. The analysis of the dislocation structure of a 3.3\% compressed single crystal shows that mainly screw dislocations with [001] type burgers vectors are present. During cooling, the martensitic R-phase grows homogeneously. On further cooling in some regions a burst like growth of B19'-neddles can be observed in addition to B19'-regions that nucleate and grow promoted by the stress-fields of dislocations. Dislocation analysis after back transformation suggests that dislocations form as a result of the martensitic transformation.
\end{abstract}

\section{Introduction}

NiTi shape memory alloys show unique mechanical properties such as pseudoelasticity, one-way effect and two way effect. These effects are based on a martensitic transformation between a high (B2) and a low temperature phase (B19') [1]. Pseudoelasticity is mostly used in medical applications, e.g. for guide wires, orthodontic wires and stents [2,3]. In Micro-Electro Mechanical Systems (MEMS) the one-way effect is exploited in actuators and sensors [4-7]. In both fields, fatigue limits the service life of shape memory components. Functional fatigue of NiTi shape memory alloys is often associated with the introduction of dislocations during cycling. It is well known that with thermal cycling of NiTi shape memory alloys the dislocation density increases [8] and the martensite start temperature $\left(\mathrm{M}_{\mathrm{s}}\right)$ decreases. Chumlyakov et. al. [9] investigated the mechanical consequences of the formation of stress induced martensite in NiTi single crystals combining tensile testing with transmission electron microscopy (TEM). They concluded that dislocations with a Burgers vector of type a $\cdot<100>$ are present with glide planes of types $\{001\}$ or $\{011\}$. Recently, Norfleet et. al. [10] investigated the stress induced transformation behavior of pseudoelastic NiTi micro pillars. In agreement with Chumlyakov they observed dislocations of type $[0-10] /[10-1]$ in the stress induced transformation zone and in the adjacent regions. However, a comparison between the growth of thermal martensite in microstructures with low and high densities of dislocations is missing. Therefore, in the present study, we compare the growth of martensite in undeformed and in deformed NiTi single crystal by directly observing local transformation events during heating and cooling in the TEM.

\section{Material and experimental procedure}

For the production of the NiTi single crystals, a nickel-rich polycrystalline alloy was prepared from high purity Ti-rods and Ni-pellets. It was melted in a vacuum induction furnance using graphite crucibles. Single crystals with a nominal Ni content of 50.4 at.\% were drawn using the Bridgman technique. The as-grown single crystals are cylindrically shaped with a diameter of about $30 \mathrm{~mm}$ and a height of about $55 \mathrm{~mm}$. The single crystals were solution annealed at $1000^{\circ} \mathrm{C}$ for $12 \mathrm{~h}$ in evacuated quartz tubes followed by water quenching. The crystals were then oriented using the EBSD technique in [111]-direction. Small cylinders (diameter $5 \mathrm{~mm}$, height $9 \mathrm{~mm}$ ) were

${ }^{a}$ e-mail: Tobias.Simonerub.de

This is an Open Access article distributed under the terms of the Creative Commons Attribution-Noncommercial License (http://creativecommons.org/licenses/by-nc/3.0/), which permits unrestricted use, distribution, and reproduction in any noncommercial medium, provided the original work is properly cited. 
cut using spark erosion. Further details of the processing of the single crystals are given elsewhere [11]. Some of the cylinders were compression tested up to different strain levels on a Zwick Z100, instrumented with a $100 \mathrm{kN}$ load cell. A crosshead displacement rate of $0.5 \mathrm{~mm} / \mathrm{min}$ was applied. The transformation temperatures in the solution annelead and compressed material states were characterized using differential scanning calorimetry (DSC) on a DSC 2920 from TA Instruments. TEM-samples were cut perpendicular to the (001) zone axis and mechanically ground to a final thickness of $100 \mu \mathrm{m}$. Electron transparency was achieved by electrochemical thinning (double-jet electropolishing, solution of $20 \%$ sulfuric acid and $80 \%$ methanol, $\mathrm{T}=20^{\circ} \mathrm{C}, 19.5 \mathrm{~V}$ ). Prior to electropolishing, the compressed samples were again subjected to short term aging $\left(200^{\circ} \mathrm{C}, 5 \mathrm{~min}\right)$ in order to retransform residual martensite. TEM observations were carried out on a Philips CM20 operating at $200 \mathrm{kV}$ together with a cooling/heating double-tilt holder (Gatan, Type 636.HD).

\section{Experimental results and discussion}

\subsection{Compression results}

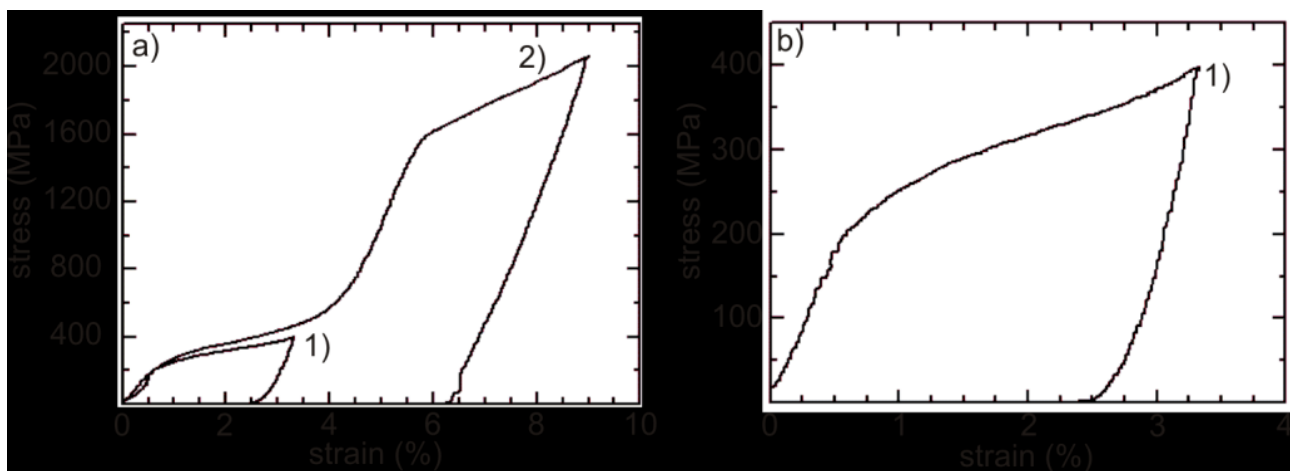

Fig. 1. a) Stress-strain curves from single crystalline cylinders in $[111]_{\mathrm{B} 2}$ compression testing with different strain levels. b) Experimental curve from experiment 1) in Figure 1 a) in higher resolution (residual strain: $2.5 \%$ ).

Fig. 1 a shows compression results for the [111]-direction. In experiment 1) the specimen was deformed up to approximately $3.3 \%$ strain reaching a maximum stress of $400 \mathrm{MPa}$. The second curve 2) shows the result of an experiment with an applied strain of approximately $9 \%$ leading to a maximum stress of $2000 \mathrm{MPa}$. Fig. $1 \mathrm{~b}$ shows the stress-strain curve of experiment 1) in Fig. 1 a at a higher resolution. A residual strain most probably due to a plastic deformation of $2.5 \%$, remains after unloading. The following in-situ TEM investigations were performed on this specimen. The shape of the compression test curves is in good agreement with results on NiTi single crystal compression testing reported earlier $[12,13]$.

\subsection{DSC results}

Fig. 2. shows the thermal transformation behavior of the single crystal in the solution annealed state and after compression testing up to $3.3 \%$ and $9 \%$, respectively. The DSC-curve of the solution annealed sample suggests a one step transformation. However, the in-situ TEM observations show that it actually transforms in two steps, from B2-phase to R-phase and then from R-phase to $\mathrm{B} 19^{\prime}$. In the $9 \%$ compressed sample a pronounced shoulder in the DSC-curve on cooling is present. For the $3.3 \%$ specimen a small increase in the $\mathrm{M}_{\mathrm{s}}$ temperature can be noticed. There is no evidence for a two-step transformation on cooling. For all material states the reverse transformation from martensite to austenite occurs in one step. Further TEM investigations were carried out on the solution annealed and $3.3 \%$ compressed material states.

Fig. 2. DSC-measurements for solution annealed and compression deformed single crystals.

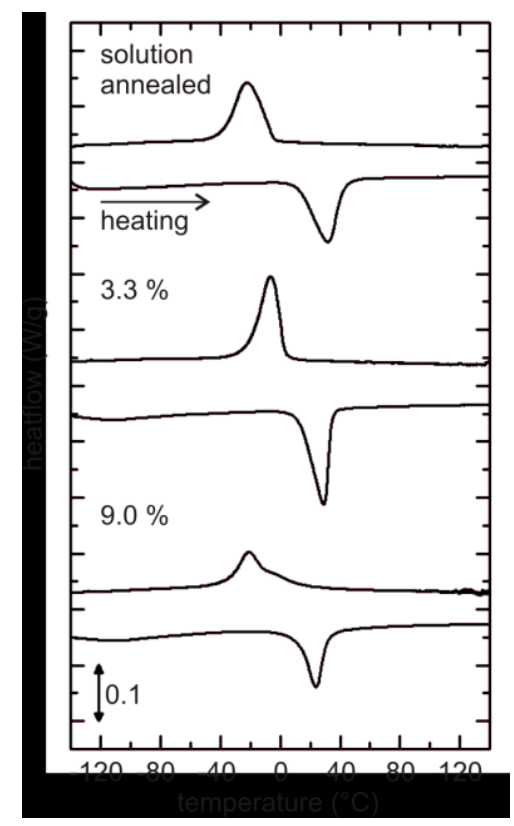




\section{3 gb-analysis and in-situ TEM in deformed and initial material state}

\subsubsection{Initial state}

Fig. 3 shows TEM bright-field images from the single crystal in the initial state after solution annealing. Fig. 3 a and $\mathrm{b}$ are taken close to the [001] zone direction, whereas Fig. $3 \mathrm{c}$ was obtained near [013]. g-vectors responsible for different contrasts are marked with black arrows. A row of in-grown dislocations is visible in Fig. 3 a. In all figures a grey spot is marked with a white arrow for reference. In Fig. 3 b and c the dislocations are invisible for the $\mathbf{g}=010$ and $\mathbf{g}=03-1$. The simple extinction rule $\mathbf{g} \cdot \mathbf{b}=0$ yields a Burgers vector of $\mathbf{b}= \pm \mathbf{a} \cdot[100]$. In this region the temperature induced martensitic transformation was studied during cooling and heating. In Fig. 4 a - d, TEM bright-field images during cooling are presented. At a temperature of $\mathrm{T}=-24.9^{\circ} \mathrm{C}$ (Fig. 4 a) a martensite needle suddenly appears. The B19'-needle is marked with a black arrow. However, it should be noted that prior to the formation of $\mathrm{B} 19^{\prime}$ at $\mathrm{T}=-2^{\circ} \mathrm{C}$, a transformation from $\mathrm{B} 2$ to R-phase occurred (not shown here). At $\mathrm{T}=-42.3^{\circ} \mathrm{C}$ (Fig. 4 b) the B19' transformation front grows into the field of observation and spreads into the matrix (Fig. $4 \mathrm{c}$ and $\mathrm{d}$ ). At a temperature of $\mathrm{T}=-60^{\circ} \mathrm{C}$, the cooling experiment was terminated. The area with short dislocation segments (Fig. 3) has completely transformed to $\mathrm{B} 19^{\prime}$. At $\mathrm{T}=-60^{\circ} \mathrm{C}$ (in the thinnest regions near to the rim of the TEM-foil) R-phase could still be detected. Fig. 4 d shows the interface between R-Phase (bright contrast) and B19' (black contrast) together with the corresponding selected area diffraction patterns obtained in the [001] direction of the former B2-phase. For the R-phase the characteristics $1 / 3<110>$ type reflections and for B19' the $1 / 2<110>$ reflections can be observed (marked with arrows). Immediately after cooling, the sample was heated back into the austenite regime (Fig. 5. a - d). The TEM-image Fig. 5 a shows the start of the reverse transformation at a temperature of $\mathrm{T}=-24.8^{\circ} \mathrm{C}$. On further heating, at $\mathrm{T}=-18^{\circ} \mathrm{C}$, the $\mathrm{B} 19^{\prime}$-regions in the vicinity of the first grown needle transform back to B2 (Fig. 5 b). With increasing temperature, at $\mathrm{T}=-15.3^{\circ} \mathrm{C}$, the B19'phase retreats (Fig. $5 \mathrm{c}-\mathrm{d}$ ). At a temperature of about $\mathrm{T}=20^{\circ} \mathrm{C}$ the $\mathrm{B} 19^{\prime}$-needle has fully disappeared. The sample was heated up to $\mathrm{T}=63^{\circ} \mathrm{C}$ and then cooled down to ambient temperature. In Fig. 6 a montage of 4 TEM images from the region of the former B19'-needle in a lower magnification together with an image taken at a higher magnification is presented. The trace of the former B19'-needle is still visible probably due to the imprint of the martensite morphology into the thin oxide layer covering the TEM foil [14]. Fig. 6 reveals that in the region of the former B19'-needle dislocations were created during the transformation. The formation of dislocations during thermal cycles in single crystals was also observed by Hurley et. al. [15].
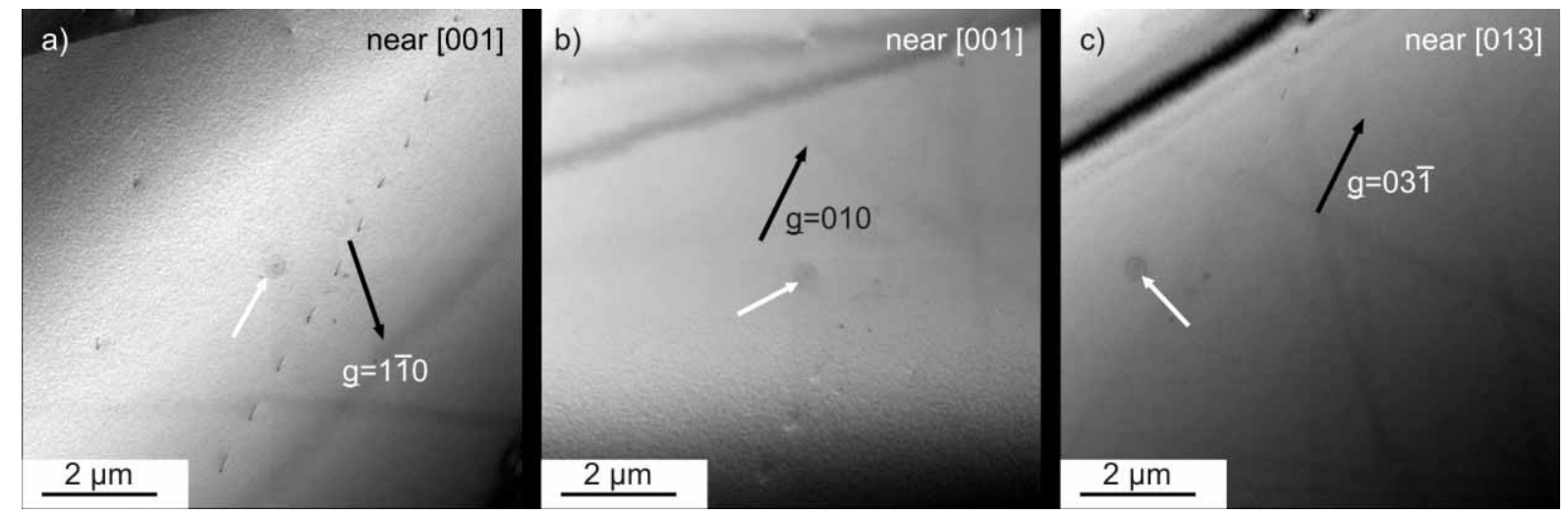

Fig. 3. a) - c) TEM bright-field images for $\mathbf{g} \cdot \mathbf{b}$-analysis. The black arrows mark the directions of the g-vectors. The white arrows mark one spot in the images for reference. In a) a row of short dislocation line segments with edge character is visible. The dislocations are invisible in the images $b$ ) and c). 


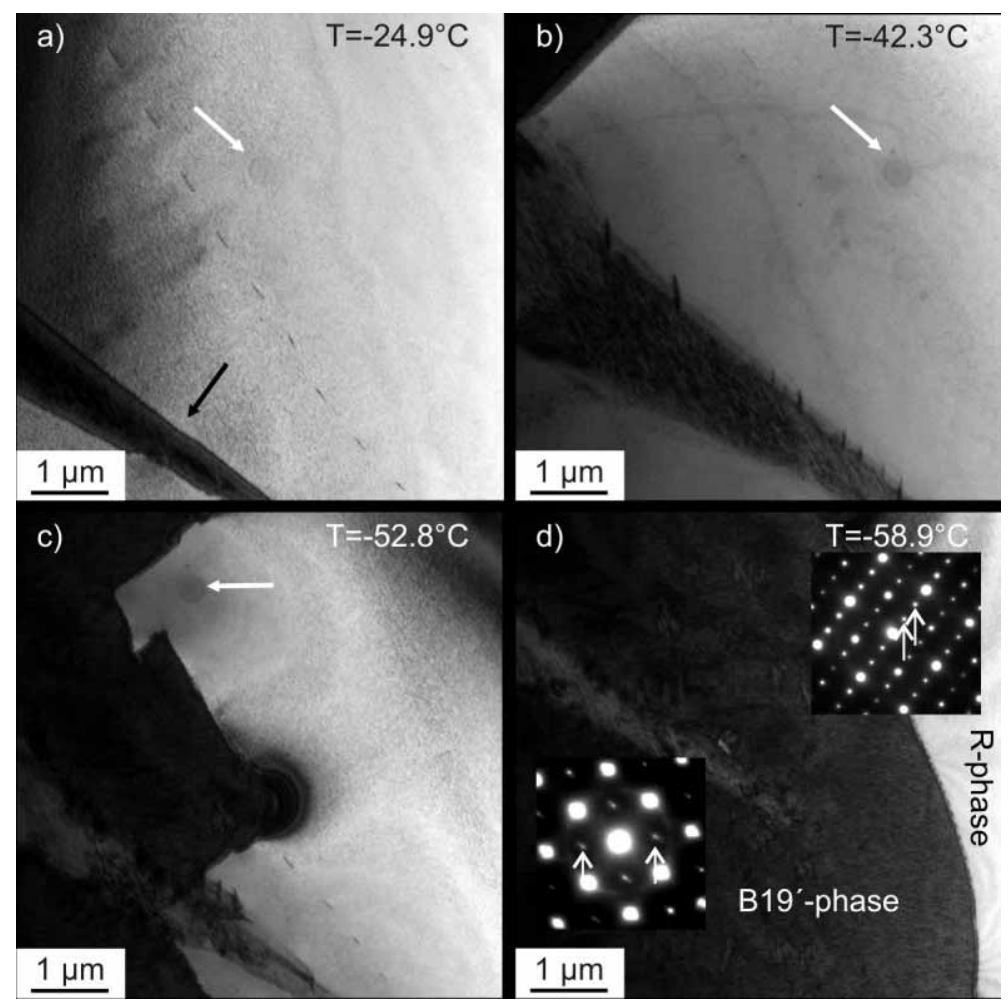

Fig. 4. a) - d) TEM bright-field images taken during in-situ TEM-cooling. a, b) A martensite B19'-needle suddenly appears and grows. c) The regions adjacent to the needle start to transform to B19' and grow with further cooling. d) TEM bright-field image of the interface between B19' (left) and R-phase (right) from the thinner rim of the TEM-foil with corresponding diffraction patterns. A reference spot is marked with a white arrow.
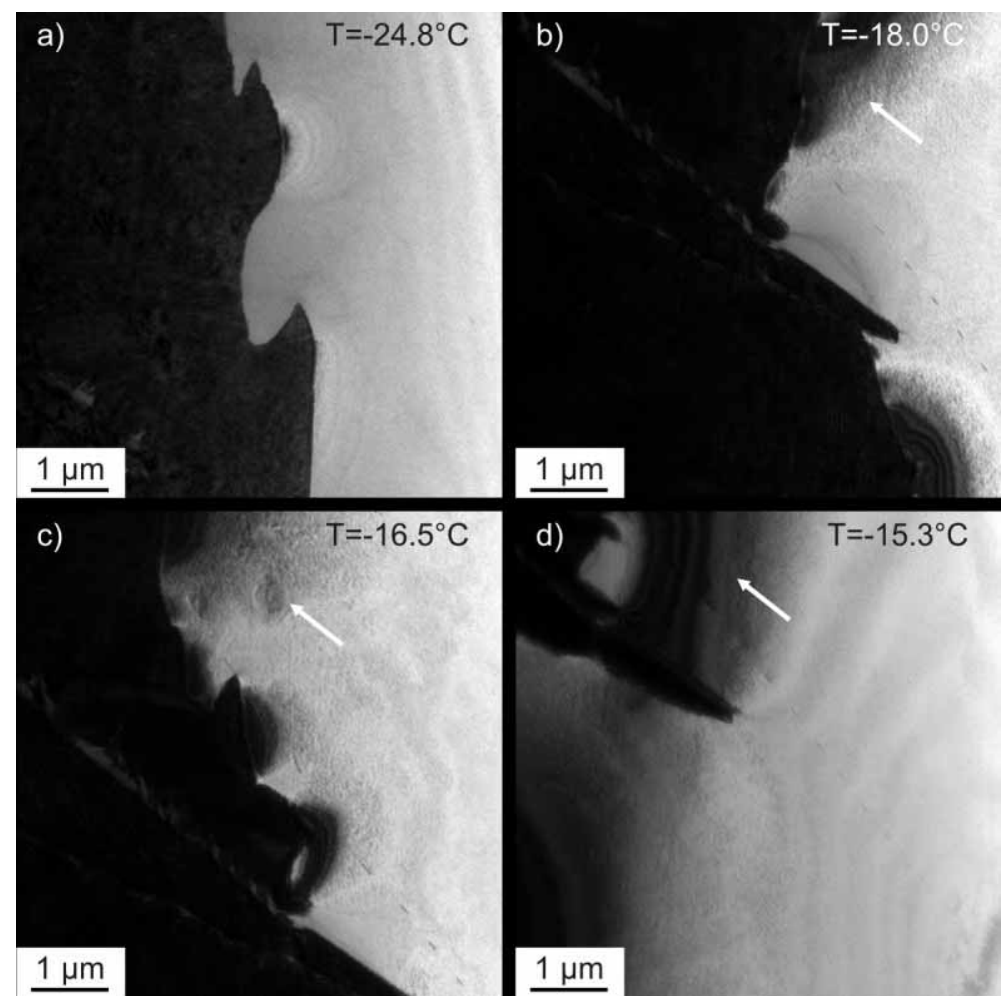

Fig. 5. a) - d) TEM bright-field images taken during in-situ TEM-heating in the temperature range from $\mathrm{T}=-24.8$ to $-15.3^{\circ} \mathrm{C}$. a) - d) B19'-regions in the vicinity of the first needle gradually transform back to B2. d) The B19'-needle itself starts to transform back to austenite. A reference spot is marked with a white arrow. 


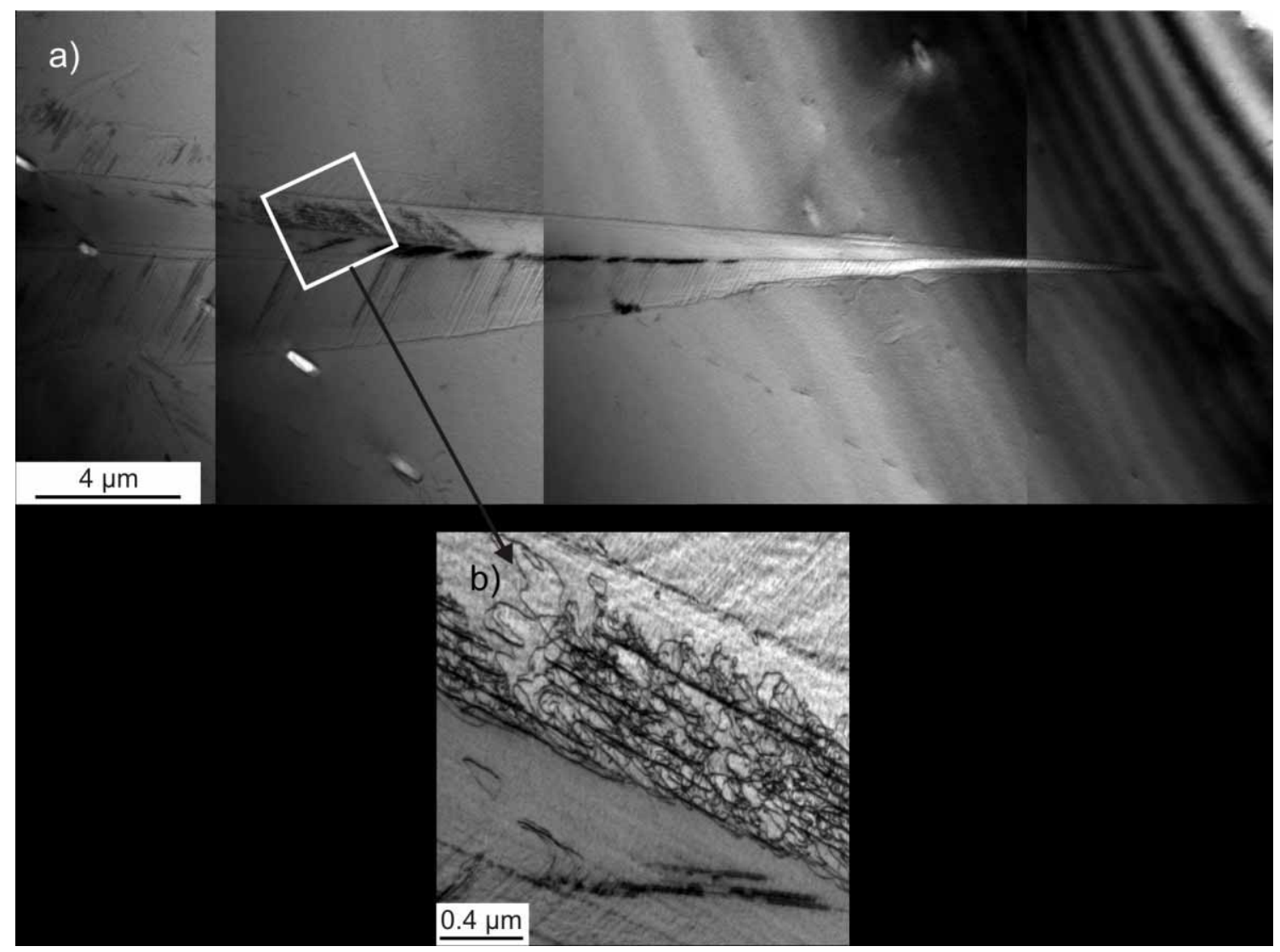

Fig. 6. a) Montage of TEM bright-field images obtained after in-situ TEM-cooling / heating. The trace of the former B19'needle (see Figs. 4 and 5) is visible. b) At a higher magnification, the region marked with a white box in Fig. 6 a) reveals the presence of transformation dislocations.

\subsubsection{Deformed material state}

Fig. 7 a) - d) shows the results of an in-situ cooling experiment performed with the $3.3 \%$ deformed NiTi single crystal. A dense arrangement of dislocations can be observed. A $\mathbf{g} \cdot \mathbf{b}$ analysis reveals Burgers vectors of type $\mathbf{b}= \pm \mathrm{a} \cdot(100)$. Screw dislocation segments are dominant. Screw dislocations in deformed NiTiMo single crystals were also reported by Chumlyakov et. al. [9]. On the upper left, a (110) shear band is marked with a white arrow in Fig. 7 a. On cooling the formation of B19' appears to be promoted by the stress fields of dislocations (Fig. 4 b and c), black arrows are highlighting such events. It should be noted here, that the sample has already transformed from B2 to R-phase at about $\mathrm{T}=-12^{\circ} \mathrm{C}$ so that a R-phase to B19' transformation occurs. With further cooling, B19' homogeneously spreads into the microstructure. As in the case of the solution annealed sample, a heating experiment up to $\mathrm{T}=60^{\circ} \mathrm{C}$ was carried out. Fig. 8 shows a comparison of the microstructure before cooling (Fig. 8 a) and after cooling (Fig. 8 b) with subsequent heating to $\mathrm{T}=60^{\circ} \mathrm{C}$. The area has fully transformed to B19' and re-transformed to B2. A change in the dislocation structure associated with this thermal cycle cannot be detected, showing the thermo-elastic character of the martensitic transformation. However, also in the deformed material state after this cooling/heating sequence, traces of the former B19'-needle remain (Fig. 9). Fig. 9 reveals a high dislocation density. From our findings in the solution annealed state it is likely that these dislocations accommodate the growth of the B19'-needle during B19'-growth. The high initial dislocation density after $3.3 \%$ deformation and the lack of sufficient microstructural statistics makes it difficult to draw quantitative conclusions and further work is required to clarify this point. 

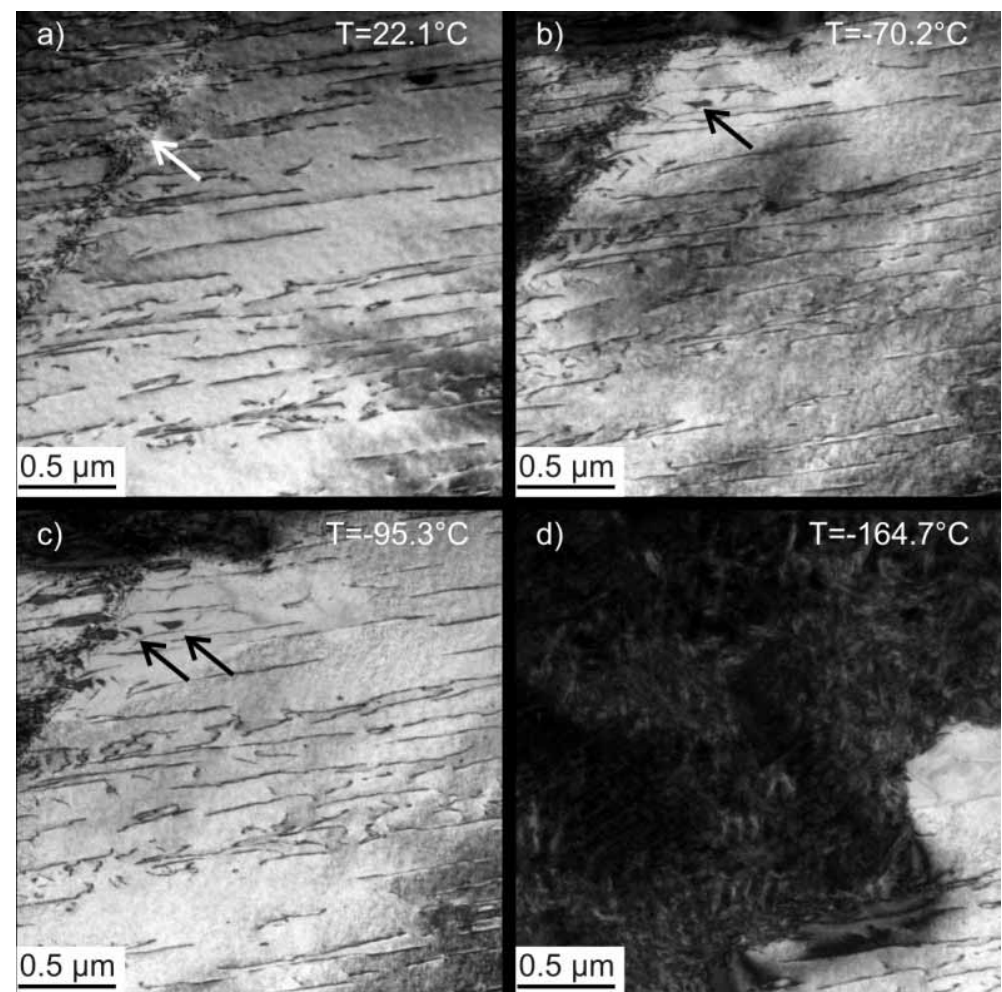

Fig. 7. a) - d) TEM bright-field images taken during cooling of the $3.3 \%$ compression deformed NiTi single crystal from $\mathrm{T}=22.1$ to $-164.7^{\circ} \mathrm{C}$. a) Initial microstructure after compression. Screw type dislocation segments are present. White arrow marks a shear band. b) and c) Growth of B19' promoted by stress fields of dislocations (marked with black arrows). d) Further growth of B19' martensite from the upper left towards the lower right.

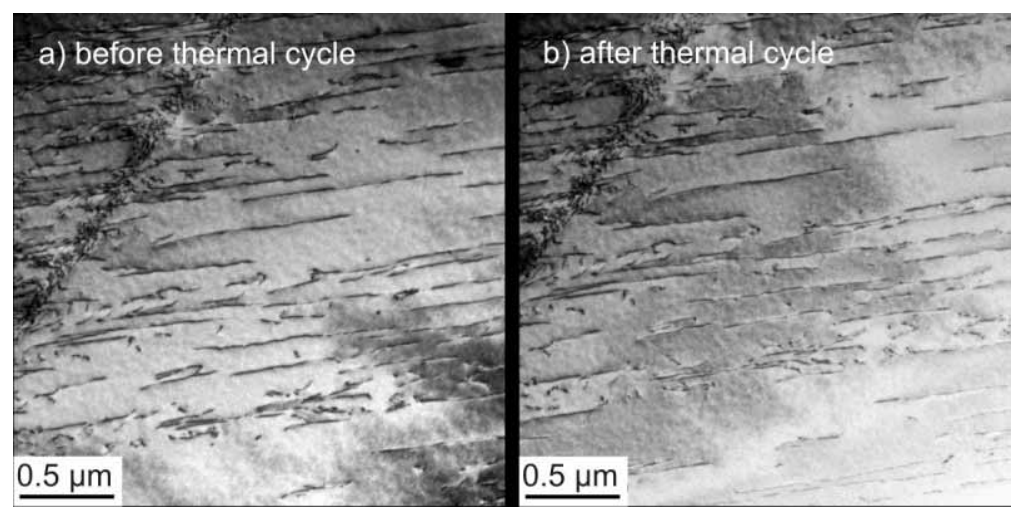

Fig. 8. TEM bright-field images of the same region before and cooling/heating of the $3.3 \%$ compression deformed NiTi single crystal. a) Before cooling. b) After cooling down to $\mathrm{T}=-165^{\circ} \mathrm{C}$, re-heating up to $\mathrm{T}=60^{\circ} \mathrm{C}$ and subsequent cooling to ambient temperature. 


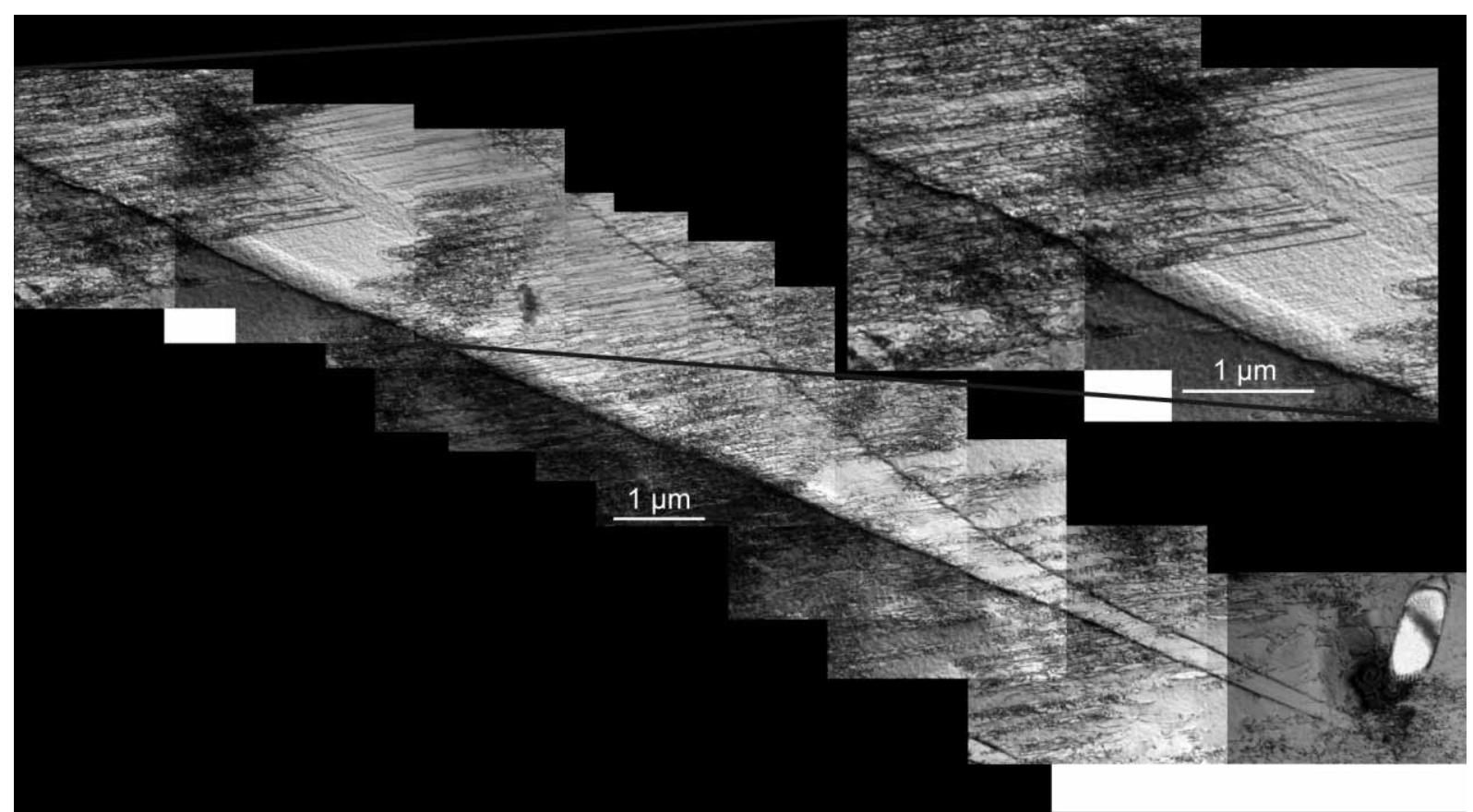

Fig. 9. Montage of TEM bright-field images taken after the in-situ TEM thermal cycle with subsequent cooling from $\mathrm{T}=60^{\circ} \mathrm{C}$ (3.3\% compression deformed NiTi single crystal), traces of the former B19'-needle are clearly visible. Dislocations decorate the region which was occupied by a B19'-needle prior to re-heating (see high magnification insert).

\section{Summary and conclusions}

$\mathbf{g} \cdot \mathbf{b}$ analysis were performed on deformed and undeformed NiTi single crystals. Dislocations with Burgers vectors of type $\mathbf{b}=[100]$ were detected. In the initial state, dislocations of edge character appear and in the compression deformed state, more screw dislocations were found, in agreement with results of Chumlyakov et. al. [9]. TEM cooling results in the growth of B19'-needles. After re-heating, associated with a back transformation to B2, dislocations which have formed during the transformation can be detected. The nucleation of martensite close to dislocations was observed.

The authors acknowledge financial support from the DFG and from the state Nordrhein-Westfalen through the collaborative research center SFB 459 (project A8).

\section{References}

[1] K. Otsuka, X. Ren, Prog. Mater Sci., 50, 511 (2005)

[2] T. Duerig, A. Pelton, D. Stöckel, Adv. Eng. Mater., A273-275, 149 (1999)

[3] F. E. Feninat, G. Laroche, M. Fiset, D. Mantovani, Adv. Eng. Mater., A4, 91 (2002)

[4] J. van Humbeeck, Adv. Eng. Mater., A273-275, 134 (1999)

[5] P. Krulevitch, A. P. Lee, P. B. Ramsey, J. C. Trevino, J. Hamilton, M. A. Northrup, JMEMS, 5, 270 (1996)

[6] J. J. Gill, D. T. Chang, L. A. Momoda, G. P. Carman, Sens. Actuators, 93, 148 (2001)

[7] Y. Liu, M. Kohl, K. Otsuka, S. Miyazaki, Adv. Eng. Mater., A378, 205 (2004)

[8] S. Miyazaki. Y. Igo, K. Otsuka, Acta Metall., 34, 2045 (1986)

[9] Y. Chumlyakov, N. S. Surikova, A. D. Korotaev, Phys. Met. Metall., 82, 102 (1996)

[10] D. M. Norfleet, P. M. Sarosi, S. Manchiraju, M. F.-X. Wagner, M. D. Uchic, P. M. Anderson, M. J. Mills, Acta Mat., 57, 3549 (2009)

[11] G. Eggeler, J. Michutta, Ch. Somsen, K. Neuking, A. Yawny, Y. Chumlyakov, Prakt. Metallogr., 36, 125 (2004)

[12] H. Sehitoglu, I. Karaman, R. Anderson, X. Zhang, K. Gall, H. J. Maier, Y. Chumlyakov, Acta Mater., 48, 3311 (2000)

[13] H. Sehitoglu, I. Karaman, X. Zhang, H. Kim, Y. I. Chumlyakov, H. J. Maier, I. Kireeva, Metall. Mater. Trans. A, 32, 477 (2001)

[14] A. Dlouhy, J. Khalil-Allafi, G. Eggeler, Phil. Mag. A, 83, 339 (2003)

[15] J. Hurley, A. M. Ortega, J. Lechniak, K. Gall, H. J. Maier, Z. MetaIlkd., 94, 547 (2003) 